\title{
Catalytic Hydrogenation of Hydrocarbons for Gasoline Production
}

\author{
Mustapha Danlami Garba ${ }^{1}$ and Ahmad Galadima ${ }^{2 *}$ \\ ${ }^{1}$ Department of Chemistry, University of Glasgow, \\ Glasgow G12 8QQ, United Kingdom \\ ${ }^{2}$ Center for Research Federal University Gusau, P.M.B. 1001, Gusau, Nigeria \\ *Corresponding author: ahmadgldm@yahoo.com
}

Published online: 25 August 2018

To cite this article: Garba, M. D. \& Galadima, A. (2018). Catalytic hydrogenation of hydrocarbons forgasoline production.J.Phys. Sci.,29(2), 153-176, https://doi.org/10.21315/ jps2018.29.2.10

To link to this article: https://doi.org/10.21315/jps2018.29.2.10

\begin{abstract}
The persistent growth in the global population has accounted for the continuous increase in the use of gasoline-based automobile engines. Although the application of gasoline additives such as tetraethyl lead (TEL), oxygenates and metal carbonyls like methyl cyclopentadienyl manganese tricarbonyl (MCT) has been considered suitable for gasoline quality upgrading, the numerous challenges that include environmental pollution and destruction to catalytic converters attributed to search for better valorisation options. The hydrogenation of hydrocarbon fractions from petroleum refining is a forefront issue recently adopted by refineries worldwide. The process involves the incorporation of suitable catalytic systems under hydrogen atmosphere to upgrade hydrocarbons into similar derivatives of better gasoline properties. The paper carefully tailored a series of recently published literature on the various aspect of the hydrogen process with emphasis to catalyst design and testing, mechanisms, industrial perspective and challenges. Areas for further investigations were also discussed.
\end{abstract}

Keywords: Hydrogenation, gasoline, catalysis, hydrocarbons, catalytic hydrogenation

\section{INTRODUCTION}

Hydrocarbon fuels are usually obtained from petroleum fractions. Depending on application and environmental constrain associated with production, they are blended with other specific hydrocarbon components to produce a variety of very high grade fuels. ${ }^{1,2}$ Meanwhile, it is a well-known fact that the major components of fuel used in internal combustion engines comprise mainly of straight chain and isomers of light and medium alkanes with specific concentration 
of aromatics due to environmental policies, but are good for the optimisation of octane number. ${ }^{1-5}$ Refinery operations generally produce several streams of products that are typically quantified as functions of hydrocarbons sources used in various processes in generating high grade fuels. However, all these products contain valuable petrochemical components which at stages of productions require improved processing to extract them in more valuable forms. Research indicated that petroleum-based fuels are popularly used as a major commodity for transportation system and industrial based applications. ${ }^{6,7}$ Research has also revealed that the global refinery construction will still grow for many decades to come despite the low margin reported for growth over supply. ${ }^{8}$ The growth was projected historically at a high rate and that by 2025 every region of the world is expected to see a refinery conversion capacity for more valuable products growing faster than distillation with only $1.3 \%$ to $2.4 \%$ per annum for distillation compared to $2.4 \%-0.5 \%$ per annum for conversion as illustrated in Figure 1.

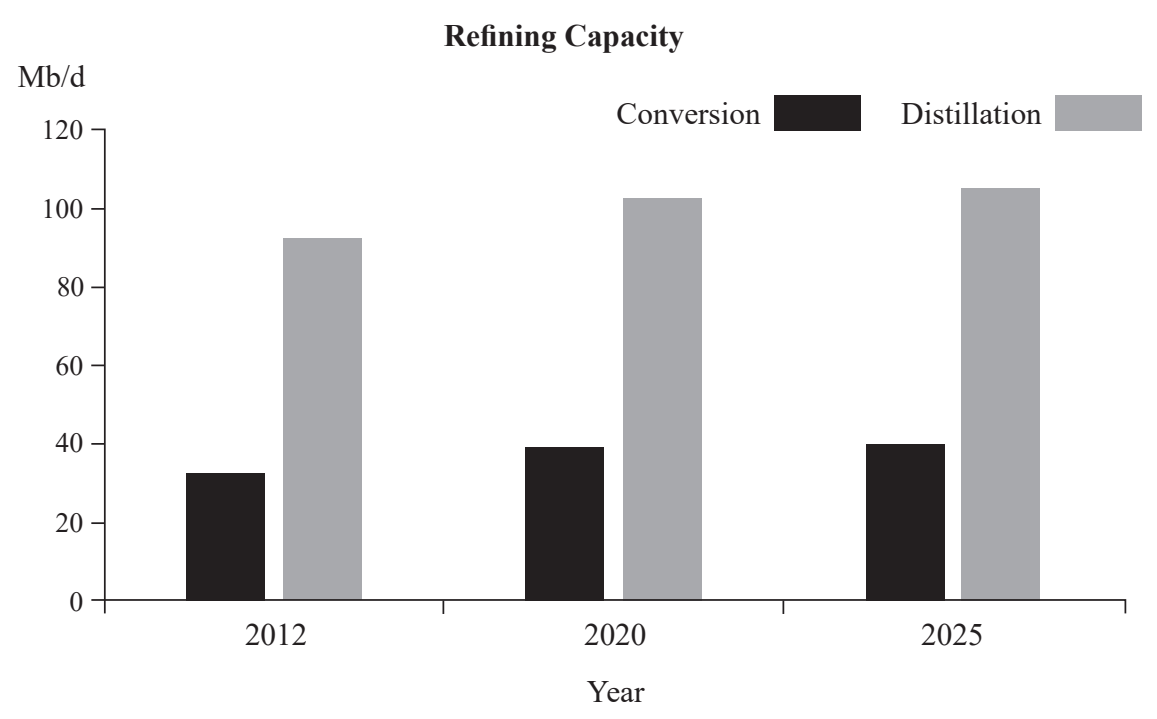

Figure 1: Global refining capacity and capacity additions. ${ }^{8}$

Generally, the global conversion/distillation ratio had been projected to grow by $\sim 10 \%$ annually. However, maximising the products will strongly depend on refining industries to devise a more satisfying route for production of high quality fuels especially for cetane/octane numbers and adherent to environmental constrains. For instance, the growth in the content of aromatic ring compounds in Fluid Catalytic Cracking Unit (FCCU) feedstock necessitates their conversions into more useful compounds. The naphthenic ring opening catalytic process accounts for monocyclic, dicyclic and polycyclo-paraffins which could be further converted into iso-paraffins by side chain reaction to maximise and produce quality fuel. ${ }^{9}$ 
Hydrogenation process is a well-known method to have been used in refinery over many decades. It has the advantage of converting various hydrocarbons to most valuable ones, ranging from dealkylation of aromatics, opening of naphthenic rings, hydrocracking of paraffin chains, removal of hetro-atoms and saturation of carbon-carbon bonds (see Scheme 1)..$^{10}$ For instance, hydrogenation reaction can proceed through the addition of adsorbed hydrogen molecule on catalyst surface to the unsaturated bonded atom to form a corresponding saturated alkane. ${ }^{11-14}$ It also has the advantage to open up an unsaturated ring and removal of hetro-atoms into any hydrocarbon formed molecules. ${ }^{15-19}$

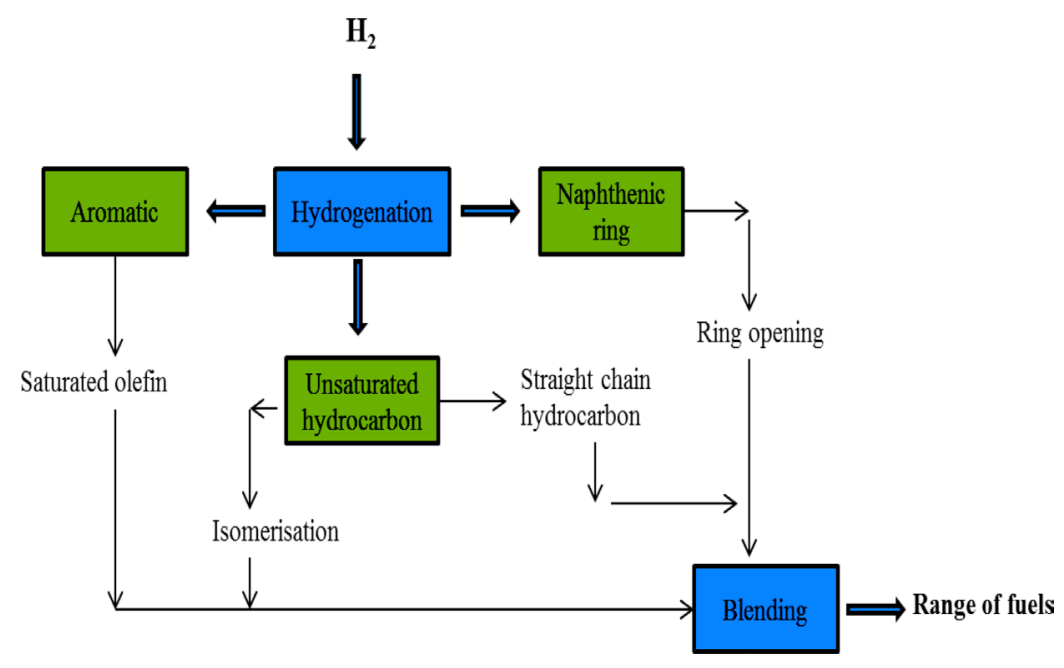

Scheme 1: Typical hydrogenation units and products for fuel range blending.

Hydrogenation is an important process in petroleum refining with an estimated economic benefit of around 6 million US dollar/year on an average scale refinery. ${ }^{20}$ The process could also be effectively utilised in the process of coal, tar sand and shale exploration that provide cleaner burning fuels. Literature works suggested many available commercial catalysts, but the catalyst systems are typically by aimed process of the hydrogenation involved in the refinery. However, each process has individual preferential selectivity, but is mainly of Mo, Ni and Co supported alumina-based catalyst system for severe hydrogenation process is well known. ${ }^{21-28}$ For instance, cobalt molybdenum is used for hydrodesulfurisation (HDS) and nickel molybdenum for hydrodenitrogenation (HDN) efficiency, but the efficacy of different catalysts used appears to be based on reactivity and effectiveness of the process. Meanwhile, other active materials such as catalyst systems of noble metals, zeolites, mesoporous molecular sieves and some other non-oxide supports have also been evaluated. ${ }^{29-35}$ 
The issues of hetro-atom removal with respect to the hydrogenation of the olefins require a special control mechanism for optimum octane rating. ${ }^{19}$ However, selectivity of the process is influenced by many factors such as the catalyst promoters for HDS, but the effect is also reported for the olefins hydrogenation and the aromatic counterparts..$^{36-41}$ The structure of the individual reactants has also been pointed out for the effective reactivity of the catalyst.

The paper presents a review on the role of heterogeneous catalyst systems for the hydrogenation (i.e., upgrading) of hydrocarbon-based fuels into blending grade ones. Emphasis would be given to catalyst development and activity evaluation during hydrogenations of unsaturated hydrocarbons, aromatics and naphthenic rings opening into paraffins. The paper will provide a baseline for identifying the progress made and the ways forward. The use of catalysts is widely known for the processes. However, the main catalyst systems were identified as cost effective especially for the necessity for conversion of hydrocarbons to more useful compounds and environmental sustainability that would be achieved. Therefore, the paper will mainly focus on these catalytic systems. Noble metals (i.e., platinum group metals like $\mathrm{Pt}, \mathrm{Pd}, \mathrm{Ru}$, etc.) and composite transition metal catalysts based on nickel, molybdenum, and cobalt and their various supported analogues were reportedly studied for hydrogenation of unsaturated hydrocarbons, aromatics and the naphthenic ring opening. The paper covers concise details on these materials, with emphasis on their activities and operation conditions. Hydrocarbons conversion into iso-paraffins on the catalyst acidic sites and factors responsible for catalyst deactivation would also be discussed.

\section{HYDROGENATION REACTION IN PETROLEUM INDUSTRY}

The hydrogenation reactions of hydrocarbon feedstocks are extensively carried out in petroleum refineries. The practice usually employs the use of metallic/ acidic catalysts at elevated temperature and hydrogen pressure conditions. The hydrogenation process in refinery constitutes versatile activities of a number of important reactions, which includes the removal of hetro-atoms such as sulphur, nitrogen and metals, saturation of olefins and aromatic, opening of naphthenic rings, and to improve the $\mathrm{H} / \mathrm{C}$ ratio in hydrocarbon range fuels. The main primary objectives are as follows:

1. Removal of sulphur from gasoline blending components to meet the recent clean fuel specifications and downstream processes.

2. Removal of sulphur from diesels and kerosene for heavy engines and home heating, respectively. 
3. Conversion of kerosene to jet fuel through mild aromatic saturation.

4. Removal of hetro-atoms for efficient catalyst activity in FCC.

5. Hydrocarbon rings opening and saturation of olefins into paraffin which could further be converted into iso-paraffins for cetane/octane improvement.

In a generic form, these refinery hydrogenation processes could be presented as shown in Scheme 2 given below:

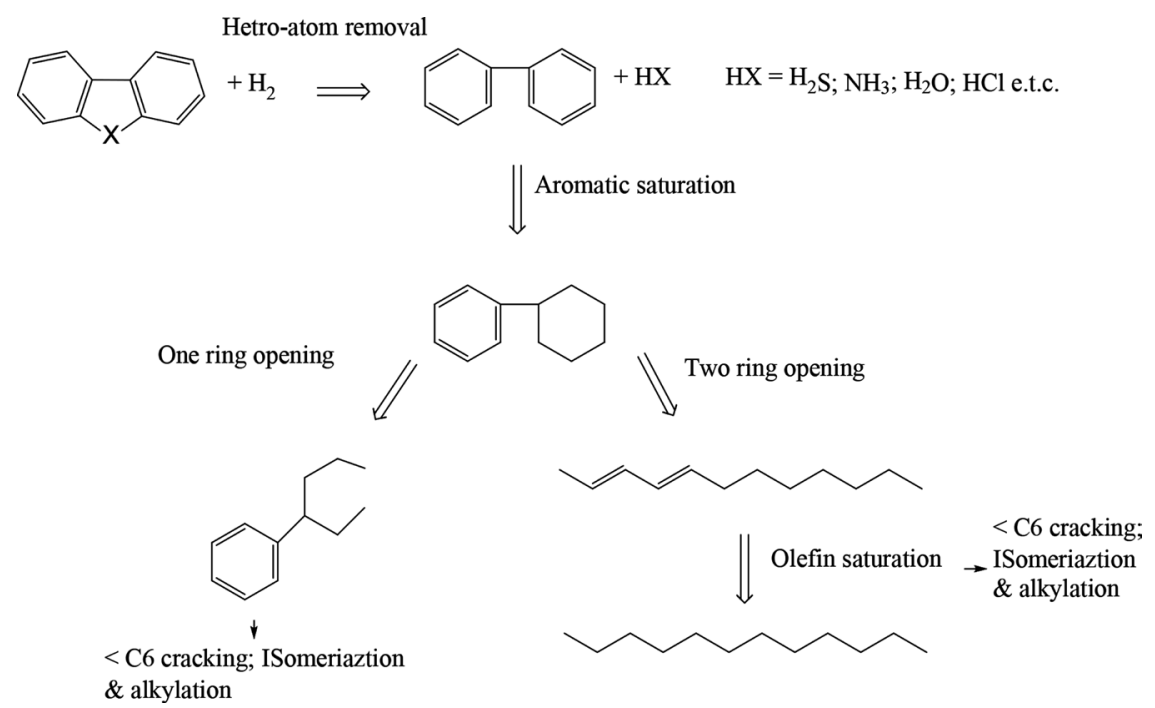

Scheme 2: A generic form of hydrogenation reactions in refinery.

\subsection{Hydrogenation of Unsaturated C4-C8 to Alkanes}

The hydrogenation reaction involved the addition of absorbed hydrogen on the catalyst surface to the unsaturated hydrocarbon in the feed and producing the corresponding paraffin. A simple generic mechanism is outlined in Scheme 3 below.

$$
\begin{aligned}
& \mathrm{C}_{\mathrm{n}} \mathrm{H}_{2 \mathrm{n}-2}(\mathrm{~g})+\mathrm{H}(\mathrm{ads}) \rightarrow \mathrm{C}_{\mathrm{n}} \mathrm{H}_{2 \mathrm{n}-1} \text { (ads) } \\
& \mathrm{C}_{\mathrm{n}} \mathrm{H}_{2 \mathrm{n}-1}(\text { ads })+\mathrm{H}(\text { ads }) \rightarrow \mathrm{C}_{\mathrm{n}} \mathrm{H}_{2 \mathrm{n}}(\mathrm{g}) \\
& \mathrm{C}_{\mathrm{n}} \mathrm{H}_{2 \mathrm{n}}(\mathrm{g})+\mathrm{H}(\text { ads }) \rightarrow \mathrm{CnH}_{2 \mathrm{n}+1} \\
& \mathrm{CnH}_{2 \mathrm{n}+1}(\text { ads })+\mathrm{H}(\mathrm{ads}) \rightarrow \mathrm{C}_{\mathrm{n}} \mathrm{H}_{2 \mathrm{n}+2}
\end{aligned}
$$

Scheme 3: Illustrative mechanism for hydrogenation of hydrocrabons. 
Hydrogenation of hydrocarbon is exothermic and produces a significant amount heat. ${ }^{42}$ However, alkynes are thermodynamically less stable than the respective alkene due to the nature of their bonding and strongly adsorb catalyst surfaces. Highly unsaturated hydrocarbons are sometimes hydrogenated into corresponding olefin depending on demands. Producing the desired alkene rather than the alkane, however, in catalytic hydrogenation, may be difficult because there are significant numbers of hydrogenation catalysts effective in promoting the addition of hydrogen but fewer are selective in that aspect. Palladium (Pd) is known to be a good metal candidate for selective hydrogenation of highly unsaturated hydrocarbon but even with Pd, catalysts may be partially deactivated as in Lindlar's catalyst or poisoned as in the addition of carbon monoxide in ethyne hydrogenation, to limit the production of the alkane. Although alkene hydrogenation is inhibited by the presence of alkynes, in the absence of the alkyne, research indicates that the alkene will react more rapidly. ${ }^{43}$ Research has also shown that in a competitive environment, the alkyne can influence the reactivity of other alkynes and alkenes. ${ }^{44,45}$ Hydrogenation of unsaturated bonds is considered a very important catalytic technique in refinery operations. Ideally, hydrogenation can be performed at low temperature of $\sim 100^{\circ} \mathrm{C}$ or below and relatively low hydrogen pressure of typically 10-15 bar in a catalyst system constituting noble metal such as $\mathrm{Pt}, \mathrm{Pd}, \mathrm{Rh}$ and $\mathrm{Ru}$. However, catalyst system constituting metals such as $\mathrm{Ni}, \mathrm{Co}, \mathrm{Sn}$ and Mo, etc., required a high temperature and high hydrogen pressure but are cheaper and more accessible.

One of the early hydrogenation reactions was performed by Bond. ${ }^{11}$ In the study, the reaction of ethylene and propylene was demonstrated. The reaction was performed using $\mathrm{Pt} / \mathrm{Al}_{2} \mathrm{O}_{3}$-support and $\mathrm{Ir} / \mathrm{Al}_{2} \mathrm{O}_{3}$-support in mild temperatures $\sim 20^{\circ} \mathrm{C}-150^{\circ} \mathrm{C}$ to observe the interaction of the olefin and the deuterium and compare to hydrogen feed to understand efficacy of the used catalyst on the hydrogenation activity of the tested olefin reactants. The interaction of the tested catalyst gives only small amount of deuteron-olefin and HD [ratio p(deuteronolefin) $/ \mathrm{p}$ (paraffin) $]<0.1$ the rate of double-bond migration relative to hydrogenation are low but the relative of olefin exchange generally increases with decreasing $\mathrm{P}_{\mathrm{H} 2, \mathrm{D} 2} / \mathrm{P}_{\mathrm{O}}$ and increasing temperature.

Boitiaux et al. worked on the liquid phase hydrogenation of unsaturated hydrocarbon 1-butene, 1,3-butadiene and 1-butyne at $20^{\circ} \mathrm{C}$ and 20 bar. ${ }^{14}$ Roughly $80 \%$ conversion was obtained during the hydrogenation of 1-butene to butane over the $\mathrm{Rh} / \mathrm{Al}_{2} \mathrm{O}_{3}$ catalyst. However, unlike reactions over $\mathrm{Pt} / \mathrm{Al}_{2} \mathrm{O}_{3}$, butane was not the sole product formed because double bond shift and isomerisation are also observed with $\mathrm{Rh} / \mathrm{Al}_{2} \mathrm{O}_{3}{ }^{46}$ High conversion was also observed with 1,3-butadiene over the $\mathrm{Rh}$ catalyst, and several other products were also observed in addition to the main 
1-butene product which includes tran-2-butene, butane and cis-2-butene. 1-butene hydrogenation also begins after a high conversion of 1,3-butadiene is achieved. The hydrogenation of 1-butyne over Rh catalyst generates only 1-butene which appears at the very beginning of the reaction. The hydrogenation reactions with Rhcatalyst are very sensitive to metallic dispersion compared with Pt and Pd catalyst. However, hydrogenation of the 1-butyne over the complete range dispersion Rhcatalyst close to $100 \%$ deactivates the catalyst. The hydrogenation of 1-butene is completely in line with the other tested catalyst with increasing activity order $\mathrm{Pt}<\mathrm{Pd}<\mathrm{Rh}$. This order remains the same with $\mathrm{Pt}$ and $\mathrm{Rh}(\mathrm{Pt}<\mathrm{Rh})$ for butadiene and butyne hydrogenation but Pd is by far more active than others.

\subsection{The Hydrogenation Activity}

\subsubsection{Hydrogenation in ring opening for gasoline fuel}

Ring opening reactions are primarily performed in the refinery to meet an increased demand in diesel products. For example, refineries in Europe have the option to blend light cycle oil (LCO) fractions from Face Centred Cubic (FCC) process to maximise the diesel production, but this does not generally meet the requirements currently placed on diesel specifications. This is because due to high amount of polyaromatics compound around $\sim 48 \%-69 \%$ and a low cetane number of $\sim 18-25$ which contradicts the European guidelines that limit the polyaromatic blending speciation to $\sim 11 \%$ and a minimum cetane number of $51 .{ }^{47}$ Therefore, the polycyclic components are hydrotreated and more significantly lowered by hydrogenation to improve the cetane number. However, ring opening was employed thereafter to further improve the cetane number and enable the light cycle oil to be more significantly used in the diesel blending. This is illustrated in Scheme 4.

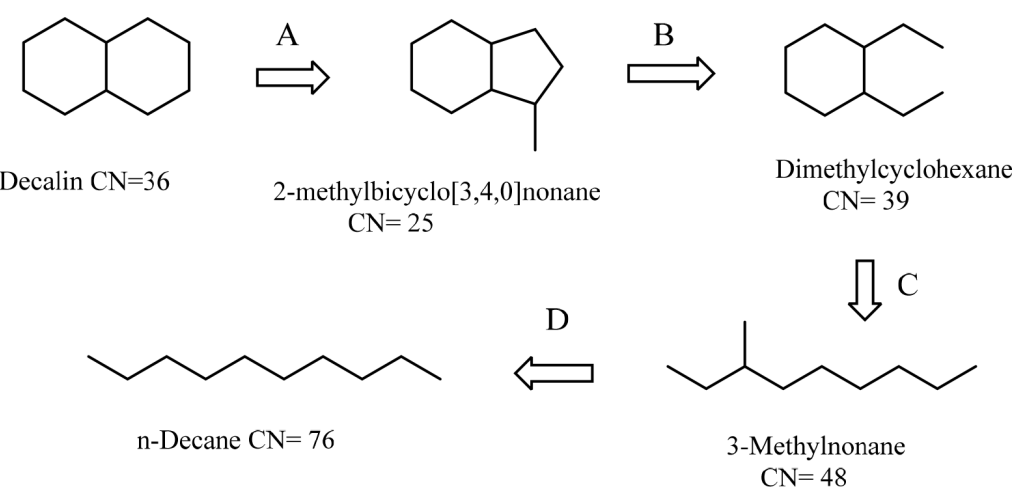

Scheme 4: Improving the cetane number of fuel via ring opening process. 
Ring opening significantly increases the cetane number of a molecule as illustrated, starting from aromatic cycle into ring molecule and converted to liner or mono branched paraffin all at the backbone of hydrogenations. Ring opening is selective towards the desire paraffin and could be done using metal, acid and bifunctional catalyst raging from simplest methylcyclohexane to a complex naphthenic ring molecule. The reaction of complex napthenic ring such as decalin and tetralin is often hindered by a number of problems in the reaction pathways due to complexity and nature of the rings. Therefore, the reaction requires more details to understand the ring opening mechanism and suitable catalyst system. ${ }^{48}$

It had been reported that some of the ring opening processes occur via sequential dehydrogenation, protonation and protolytic-dehydrogenation which then crack to produce the open structured hydrocarbons. Others include isomerisation reaction, hydrogenation and hydride transfer because the reaction mechanism involves hydrogenation acid mediated cracking and isomerisation. However, the widely known method is performed via acid catalysed ring opening widely studied on zeolites. Several studies have been performed to study the acid catalysed ring opening of decalin which revealed that decalin opening using zeolites occurs by ring contradiction via isomerisation as illustrated in Scheme 5.9-53

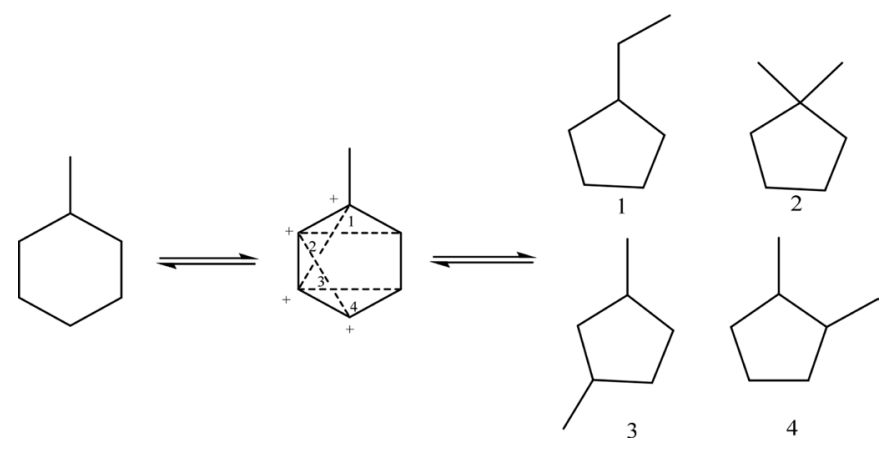

Scheme 5: Illustration of ring contradiction and skeletal isomerisation using cyclohexane as a model compound.

Studies by Kubička et al. reveals that the activities are usually Bronsted influential and were best obtained with moderate Bronsted acidity catalyst such as $\mathrm{H} \beta$ 25, H $\beta-75$ and HY-12 zeolite. ${ }^{50}$ There is nearly no activity reported for catalyst with low Bronsted acidity such as MCM-41[50]. However, fast deactivation is recorded with strong Bronsted acid catalyst such as (H-mordenite-20) due to coke deposition. Generally, ring opening observed over acid catalyst proceed via the Bronsted acid sites and performed by protolytic dehydrogenation followed by carbenium ion formation through ring contradiction, $\beta$-scission, alkylation and hydride transfer. ${ }^{50,54}$ 
Selectivity of ring opening of naphthenic molecule is investigated using several metals. McVicker et al. studied the selectivity using $\mathrm{Ru}, \mathrm{Rh}, \mathrm{Ni}$, Ir and Pt, and reported that $\mathrm{Rh}, \mathrm{Ni}$ and $\mathrm{Ru}$ showed similar preferences over the cleaving of unsubstituted $\mathrm{C}-\mathrm{C}$ bonds. ${ }^{55} \mathrm{Ir}$ showed high selectivity compared to the all tested metals, while Pt metal showed less selectivity but can cleave the substituted C-C bond. Approximate statistical production distributions were formulated by Gault. ${ }^{56}$

Another similar investigation showed that metals such as Rh, Ir, Pd and Pt may improve single hydrogenolysis among eleven studied catalysts. ${ }^{57}$ In a cited example, hydrogenolysis of 3-methylpentane and methylcyclohexane was obtained using these metals. It was revealed that the isomerisation, $\mathrm{C} 5$ ring opening and closure activity of these catalysts (Rh, Ir, Pd and Pt) could be correlated to their FCC structure and atomic dimensions. However, when $\mathrm{Co}, \mathrm{Ni}, \mathrm{Ru}, \mathrm{Cu}, \mathrm{Re}, \mathrm{Ag}$ and $\mathrm{Os}$ were employed, multiple fragmentations were observed leading to formation of less than 7-carbon atoms. Meanwhile, literature showed that Ir catalysts have high activity and selectivity toward ring opening of $\mathrm{C} 5$ and $\mathrm{C} 6$ monocyclic molecules, but several reports show that $\mathrm{C} 6$ ring opening of molecule is enhanced by the use of bifunctional catalyst. ${ }^{55,58-65}$ This also followed the mechanism of the C6 to C5 contradiction on the acid site and the openings of the $\mathrm{C} 5$ ring on the metal site. ${ }^{55}$

Ring opening of naphthenic molecule had been reported to occur via three distinct processes:

1. Non-selective mechanism involving the cleavage of the $\mathrm{C}-\mathrm{C}$ bond of the ring with an equal chance of breaking any of the $\mathrm{C}-\mathrm{C}$ bonds in the ring.

2. Selective mechanism involving the breaking of only unsubstituted $\mathrm{C}-\mathrm{C}$ bonds usually known as dicarbene mechanism.

3. Partially selective mechanism involving the competing of both the nonselective and the selective mechanism as explained above.

The reaction condition employed were typically $\sim 380^{\circ} \mathrm{C}$ and $\sim 3 \mathrm{MPa}$ pressure. However, temperatures between $250^{\circ} \mathrm{C}-400^{\circ} \mathrm{C}$ and pressures between $2-5 \mathrm{MPa}$ were also claimed. Arribas et al. studied the conversion of tetralin under temperature conditions of $250^{\circ} \mathrm{C}-325^{\circ} \mathrm{C}$ in the presence of hydrogen gas as a co-feed. ${ }^{66}$ It was observed that high activity of catalyst was obtained at high temperature reaching $(>95 \%)$ and production of high cetane number products was also achieved reaching to about $\sim 20 \%$ due to significant cracking activity expected to occur at high temperatures. However, this also relates to the topology of the zeolite support used as further argued in similar work. 
Several literature results revealed that good support and active metal combination are very critical in achieving optimal ring opening reactions. The effect of $\mathrm{Al}_{2} \mathrm{O}_{3}$ and $\mathrm{SiO}_{2}-\mathrm{Al}_{2} \mathrm{O}_{3}$ support was reported by on the activity of $\mathrm{Rh}-\mathrm{Pd}$ catalyst for the conversion of decalin at $350^{\circ} \mathrm{C}$ and $3 \mathrm{MPa} .{ }^{67}$ The gasoline conversion of the decalin and the selectivity of the ring opening products were increased using the $\mathrm{SiO}_{2}$ $\mathrm{Al}_{2} \mathrm{O}_{3}$ support ( $\mathrm{Rh}-\mathrm{Pd} / \mathrm{SiO}_{2}-\mathrm{Al}_{2} \mathrm{O}_{3}$ ) to $\sim 45.9 \%$ and $\sim 55.8 \%$ respectively compared with $\sim 19.3 \%$ conversion and $\sim 5.4 \%$ selectivity over the $\mathrm{Rh}-\mathrm{Pd} / \mathrm{Al}_{2} \mathrm{O}_{3}$ catalyst. This signifies that promoting the acidity of a catalyst produces better activity. In another related investigation, it was revealed that $\mathrm{Al}_{2} \mathrm{O}_{3}$ support could make a better $\mathrm{Rh}-\mathrm{Pd}$ catalyst for the conversion of methylcyclohexane at $400^{\circ} \mathrm{C}$ and 3.9 MPa compared with $\mathrm{Rh}-\mathrm{Pd} / \mathrm{SiO}_{2}$ catalyst. ${ }^{68}$ About $\sim 99 \%$ conversion was obtained with $\mathrm{Rh}-\mathrm{Pd} /$ $\mathrm{Al}_{2} \mathrm{O}_{3}$ compared with $\sim 80 \%$ obtained with $\mathrm{Rh}-\mathrm{Pd} / \mathrm{SiO}_{2}$ catalyst. Zirconia was also reported to be a good support for bifunctional catalyst. ${ }^{69}$ Zirconia has the ability of fine tuning acidity by controlled $\mathrm{W}$ deposition. Nonetheless, zirconia is not a typical industrial catalyst support due to textural and mechanical constraints. However, Lecarpentier et al. and Lecarpentier revealed that Ir deposit on WOx/ $\mathrm{ZrO}_{2}$ support gives high performance bifunctional $\mathrm{Ir} / \mathrm{WO}_{3} / \mathrm{ZrO}_{2}$ catalyst for selective ring opening reaction of methylcyclohexane..$^{58,70}$

Dopants were also reported to enhance the selectivity and activity of a ring opening catalyst. The use of alkali metals to influence decalin conversion and selectivity to ring opening products was reported..$^{71}$ From the investigations, Ir/ H- $\beta$ zeolite was exemplified as the catalyst material. When the catalyst was doped with various alkali metals, best conversion and selectivity were obtained with $\mathrm{Ir} / \mathrm{Rb} / \mathrm{H}-\beta$ doped catalyst about $100 \%$ conversion and $52 \%$ selectivity. Whereas, the least conversion and selectivity were obtained with $\mathrm{Ir} / \mathrm{Li} / \mathrm{H}-\beta$ doped catalyst, about $78 \%$ conversion and $37 \%$ selectivity. This showed that $\mathrm{Rb}$ species were more active compared to the other alkali species in the group. The dopants generally modify the acid sites of the $\mathrm{H}-\beta$ material and also reduce the cracking process of the reaction as shown in the paper. In another related paper, influence of $\mathrm{Na}$ addition on $\mathrm{Pt}-\mathrm{Ir} / \mathrm{Al}_{2} \mathrm{O}_{3}$ catalyst was studied on the reaction selectivity of ring opening of decalin and cyclopentane. It was revealed that the interaction between the Pt and Ir metals increases with the presence of the doped-Na and as a result, the catalytic properties of the catalyst was also modified. Increase ratio of (parameters of demanding/not demanding) reaction was achieved with the Na concentration. Three different doped catalysts were prepared ( $1 \% \mathrm{Pt}-2 \% \mathrm{Ir}-0.5 \% \mathrm{Na}, 1 \% \mathrm{Pt}-2 \% \mathrm{Ir}-1 \% \mathrm{Na}$ and $1 \% \mathrm{Pt}-2 \% \mathrm{Ir}-1.5 \% \mathrm{Na})$. When the catalysts was doped with various concentration of the $\mathrm{Na}$, increase in conversions was obtained ( $\sim 80 \%-95 \%)$ compared with $\sim 40 \%$ obtained with the catalyst without the $\mathrm{Na}$ (Figure 2). Selective reaction mechanism was also favoured and formations of 2-methylpentane and 3-methylpentane were achieved from the methylcyclopentane reaction. About $\sim 58 \%$ and $\sim 26 \%$ selectivity were 
respectively obtained compared with $\sim 26 \%$ and $\sim 16 \%$ respectively from catalyst without the doping $\mathrm{Na}^{72}$

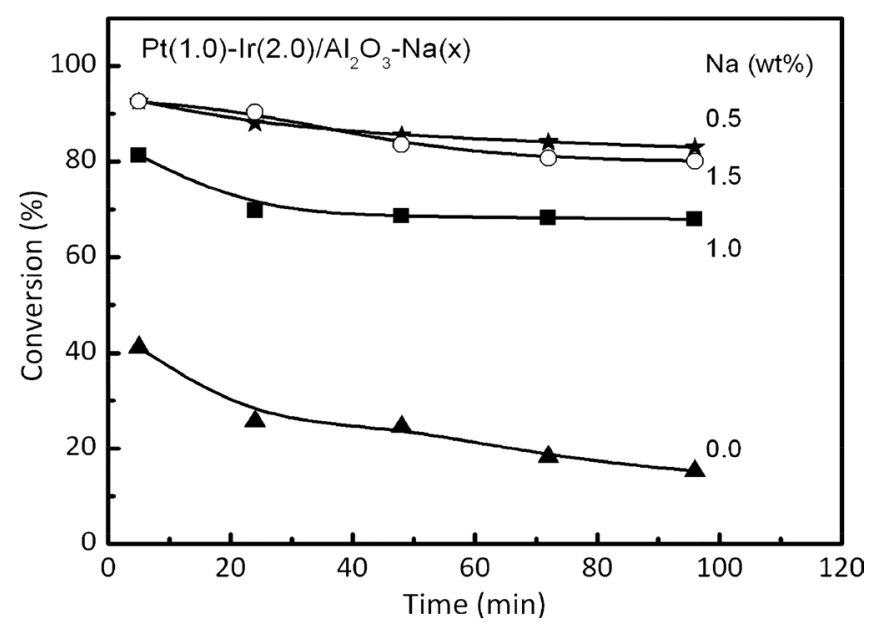

Figure 2: Conversion values as a function of time obtained in the methylcyclopentane reaction of $\mathrm{Pt}(1.0)-\operatorname{Ir}(2.0) / \mathrm{Al}_{2} \mathrm{O}_{3}-\mathrm{Na}(\mathrm{x})$ catalysts. $^{72}$

\subsubsection{Hydrogenation of aromatics to gasoline fuels}

The shift in the valorisation of heavy hydrocarbons by ring opening processes could be very valuable in the production of high octane gasoline fuels. This could also be achieved through the ring cleaving of multi nuclear aromatic composition and their derivatives. The presence of polycyclic naphthenes and aromatic hydrocarbons in gasoline fuels are considered highly undesirable due to legislative restriction placed on them, particularly on benzene concentration in gasoline fuel because of serious environmental threat. The aromatic components are very much in FCC diesel fuel $(\sim 60 \% \mathrm{v} / \mathrm{v})$ and do not only produce undesired emission exhaust gases but also affect the cetane number (Scheme 4$){ }^{73}$ Therefore, improving the quality of the fuel through selective opening of the aromatic ring with the formation of the same carbon atom as the starting hydrocarbon could be achieved. The ring opening is also profoundly relevant to the conversion of heavy hydrocarbon materials containing aromatics that allows the synthesis of high octane iso-praffins. Supported noble metal catalysts are widely known for the hydrogenation activity in aromatic hydrogenation at moderate reaction temperature and pressure.

The hydrogenation of benzene into cyclohexane had been reported in different published works. ${ }^{74-77}$ There is scant or almost no literature on the hydrogenation ring opening of benzene as this is virtually not studied. However, data on the opening of cyclohexane could be accessed for easier evaluation but almost no work has 
been performed on the direct conversion of benzene into paraffins. Onyestyák et al. reported the hydrogenation of benzene over $\mathrm{Ru} / \mathrm{Al}_{2} \mathrm{O}_{3}$ catalyst at mild condition temperatures of $130^{\circ} \mathrm{C}-220^{\circ} \mathrm{C} .{ }^{74}$ The paper further shows that the hydrogenation consumption is elevated in the process relative to the ring opening of cyclohexane. The hydrogenation of the benzene occurs quite quickly and subsequently to the conversion of the generate cyclohexane and to the corresponding paraffin compound as illustrated in Figure 3.

In a related research conducted to study the conversion of benzene into ring opening using $\mathrm{Ru} / \mathrm{Al}_{2} \mathrm{O}_{3}, \mathrm{Ir} / \mathrm{Al}_{2} \mathrm{O}_{3}$ and $\mathrm{Rh} / \mathrm{Al}_{2} \mathrm{O}_{3}$ catalyst, the reactions were shown to proceed in accordance with Figure 3, illustrating conversions passing through cyclohexane before ring opening. It was also revealed that there is a typical temperature dependence of the products yield over the main benzene conversion from the used catalyst.

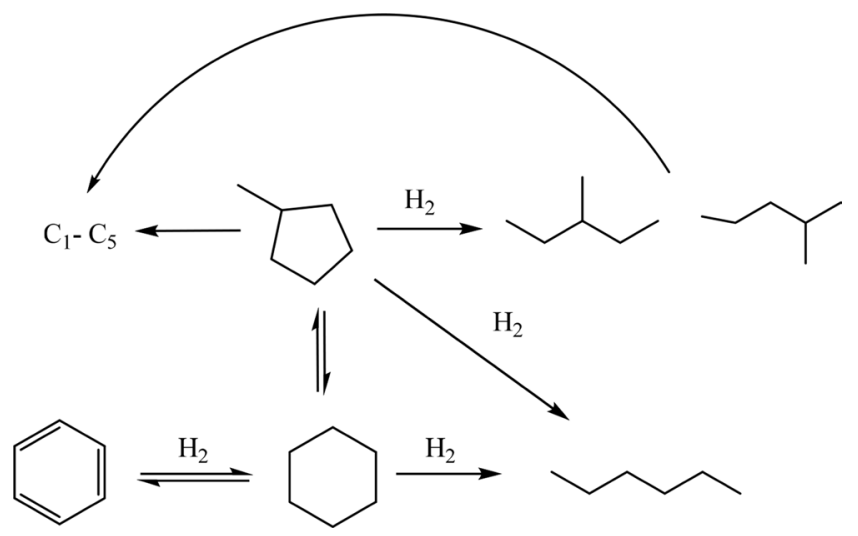

Figure 3: Benzene hydrogenation to cyclohexane and to the corresponding paraffin.

Other aromatic compounds also follow a similar mechanism with benzene, but additional possible reactions are observed and the schemes are more complicated than the ordinary benzene molecule. For example, the hydrodemethylation of toluene into cyclohexane occurs at low temperature $\left(\sim 100^{\circ} \mathrm{C}\right)$ over Pt catalyst and hydrodemethylation of toluene to benzene occurs at higher temperature $\left(>380^{\circ} \mathrm{C}\right) . .^{78}$ $\mathrm{Fu}$ et al. report the activity of $\mathrm{Ni} / \mathrm{HY}$ zeolite catalyst in the conversion of toluene into ring opening products at $350^{\circ} \mathrm{C}-450^{\circ} \mathrm{C}$ and $3 \mathrm{MPa}$ pressure. ${ }^{79}$ The paper further reveals that the activity of the catalyst in this respect increases with an increase in nickel loading. The conversion of the tested toluene reactant increases with the increase in $\mathrm{Ni}$ content and so are the products of the aromatic ring opening (AO), while the product disproportionation (D) decreases greatly. HY and USY zeolites were also tested for comparison as presented in Table 1 . 
Table 1: Efficacy of Ni content on toluene hydrogenation activity. ${ }^{78}$

\begin{tabular}{lcccc}
\hline \multirow{2}{*}{ Catalyst } & \multirow{2}{*}{ wt\% Ni } & \%Conv. & \multicolumn{2}{c}{ \%Selectivity } \\
\cline { 4 - 5 } NiHY-1 & 1.25 & 48.5 & 0.8 & 63.6 \\
NiHY-2 & 1.5 & 59.1 & 4.6 & 47.7 \\
NiHy-3 & 2.0 & 66.0 & 19.3 & 17.5 \\
HY & - & 0.63 & - & - \\
USY & - & 46.3 & - & 74.8 \\
\hline
\end{tabular}

In another related study, a different type of catalyst was tested $\left(\mathrm{Ni}_{2} \mathrm{Mo}_{3} \mathrm{~N} /\right.$ zeolite $)$ for the hydrogenation opening of aromatic compounds to observe changes using different zeolite supports. ${ }^{80}$ The various zeolites (USY, H-beta, HZSM-5 and HMCM-41(Al)) were used for this evaluation and emphasis in the differential ring opening was made due to acidity and pore size of the catalyst. The pure $\mathrm{Ni}_{2} \mathrm{Mo}_{3} \mathrm{~N}$ was reported to show low activity of hydrogenation with no ability to ring opening. Relatively high activity was obtained using H-Beta and USY zeolite supports in the opening of the aromatic substrate with about $\sim 90 \%$ conversion achieved at $430^{\circ} \mathrm{C}$ and $3 \mathrm{MPa}$.

The ring opening of benzene molecule is presumed identical to that of cyclohexane ${ }^{81}$ However, strong adsorption of aromatic compound on the surface of catalyst may subsequently attribute to the blocking of acid site. Therefore, as the hydrogenation of cyclohexane molecules proceed usually quickly and selectively in many ring opening reactions, this might not be the same with the aromatic counterpart especially at high pressure. The benzene hydrogenation to cyclohexane molecule is usually the first in the ring opening of benzene. However, cyclohexane has a very low octane/cetane number and therefore need to further isomerise the molecule or open the ring to produce paraffin range hydrocarbon molecule. Several studies have been performed on hydrogenation, isomerisation and ring opening of aromatics. ${ }^{75,77,80-84}$ Reaction performed by Shimizu et al. on benzene hydrogenation and isomerisation using Pt-supported solid acid catalyst at $250^{\circ} \mathrm{C}$ showed that benzene almost completely converted with all the Pt-supported catalyst. ${ }^{75}$ However, reaction without any catalyst and with only sulphated zirconia showed very little hydrogenation. On the other hand, reaction with $\mathrm{Pt} / \mathrm{ZrO}_{2}$ showed no isomerisation to methylcyclopentane. About $46 \%$ isomerisation conversion was achieved using $\mathrm{Pt} / \mathrm{SO}_{4}{ }^{2-} / \mathrm{ZrO}_{2}$ catalyst which is much higher than what was observed with the other tested catalysts $\left(\mathrm{Pt} / \mathrm{SiO}_{2}-\mathrm{Al}_{2} \mathrm{O}_{3}, \mathrm{Pt} / \mathrm{HY}-5.6\right.$ and $\left.\mathrm{Pt} / \mathrm{HM}-10\right)$. The reaction isomerisation of the methylcyclopentane did not occur using either $\mathrm{ZrO}_{2}$ and or Pt/ZrO $\mathrm{Zn}_{2}$ while HY-5.6 and HM-10 showed only $2 \%$ and $30 \%$ conversions, 
respectively. $\mathrm{SO}_{4}^{2-} / \mathrm{ZrO}_{2}$ catalyst showed increase isomerisation percentage of $46.2 \%$. This shows that benzene hydrogenation and isomerisation at $250^{\circ} \mathrm{C}$ are better on the $\mathrm{Pt} / \mathrm{HY}$-zeolites and $\mathrm{Pt} / \mathrm{H}$-moderate catalyst with the isomerisation activity only significant with $\mathrm{SO}_{4}^{2-} / \mathrm{ZrO}_{2}$ which make the sulphated group required for the cyclohexane isomerisation. In a related study, $\mathrm{Au}-\mathrm{Pd} / \mathrm{SiO}_{2}-\mathrm{Al}_{2} \mathrm{O}_{3}$ catalyst was used to study the hydrogenation of toluene and naphthalene. ${ }^{82}$ It was shown that hydrogenation of toluene is more difficult compared with naphthalene because of the decrease in resonance energy per aromatic ring and also differences in $\pi$-electrons cloud density due to the attached methyl group. Five different supports were used for the hydrogenation of toluene which involves varying the $\mathrm{Al}$ content (\%) (SA-0, SA-8, SA-14, SA-28 and SA-100). The $\mathrm{SiO}_{2}-\mathrm{Al}_{2} \mathrm{O}_{3}$ catalyst carrier showed a clear enhancement in the hydrogenation of the toluene compared with the $\mathrm{Al}_{2} \mathrm{O}_{3}$ and $\mathrm{SiO}_{2}$ counterpart system under the selected conditions 5.0 MPa pressure, $523 \mathrm{~K}$ temperature and $41.2 \mathrm{~h}^{-1} \mathrm{WHSV}$. The hydrogenation with SA-8, SA-14 and SA-28 significant turnover frequencies (TOF) compared with other tested catalyst is presented in Figure 4 which is abstracted from Venezia et al. ${ }^{82} \mathrm{Au}$ in hydrogenation activity has also been previously claimed because $\mathrm{Au}$ d-bands nearly have no ability of dissociate hydrogen molecules. ${ }^{85-91}$

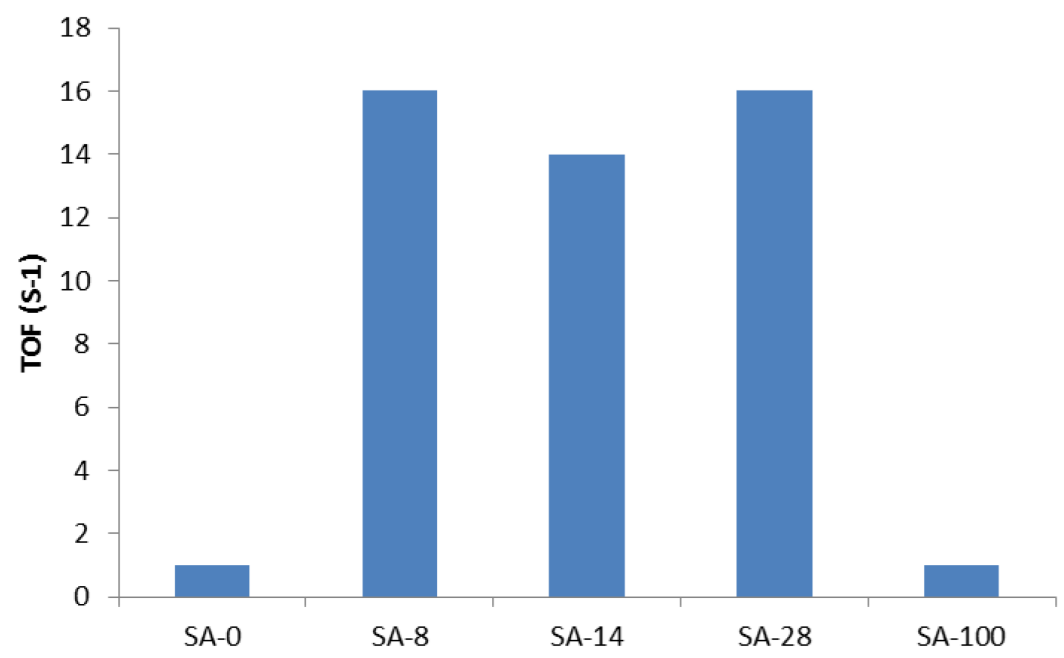

Figure 4: Calculated TOF for the toluene hydrogenation. ${ }^{82}$

Lin et al. performed the hydrogenation of benzene over Pt dispersed on $\mathrm{SiO}_{2}$, $\eta-\mathrm{Al}_{2} \mathrm{O}_{3}, \mathrm{SiO}_{2}-\mathrm{Al}_{2} \mathrm{O}_{3}, \mathrm{TiO}_{2}$ and powdered Pt catalyst. ${ }^{77}$ It was shown that the activation energies and the reaction order of the various reactions were independent of the used support. Values between 10-13 Kcal mol ${ }^{-1}$ were obtained with partial pressure dependencies $\sim 0.6 \pm 0.1$ on $\mathrm{H}_{2}$ and $0.1 \pm 0.1$ on benzene $317 \mathrm{~K}$ and $356 \mathrm{~K}$ temperatures respectively. The acidic support catalyst produced high 
activities at $333 \mathrm{~K}$ under 50 torr benzene and 685 torr $\mathrm{H}_{2}$. A frequency turnover of $\sim 0.078 \mathrm{~s}^{-1}$ was achieved with $\mathrm{Pt} / \mathrm{TiO}_{2}$ catalyst compared with $0.015 \mathrm{~s}^{-1}$ achieved with $\mathrm{Pt} / \eta-\mathrm{Al}_{2} \mathrm{O}_{3}$ catalyst. The support acidity decreases in the order $0.95 \%$ $\mathrm{Pt} / \mathrm{TiO}_{2}>0.24 \% \mathrm{Pt} / \mathrm{SiO}_{2}-\mathrm{Al}_{2} \mathrm{O}_{3}>0.96 \% \mathrm{Pt} / \mathrm{SiO}_{2}>\mathrm{Pt} / \eta-\mathrm{Al}_{2} \mathrm{O}_{3}$. However, a large increase was observed under 35 torr benzene pressure.

Catalyst treatment was also reported to enhance the hydrogenation activity of aromatic hydrogenation. Studied conducted by Ali et al. on benzene and toluene hydrogenation into cyclohexane and methylcyclohexane respectively between $50^{\circ} \mathrm{C}-250^{\circ} \mathrm{C}$ temperature range was exemplified. ${ }^{83}$ The investigated catalyst $0.35 \% \mathrm{Pt} / \mathrm{Al}_{2} \mathrm{O}_{3}$ was modified by using second metals $\mathrm{Ir}, \mathrm{Rh}, \mathrm{Re}$ and $\mathrm{U}$ and then treated via chlorination and fluorination with different halogenation contents of $1 \mathrm{wt} \%, 3 \mathrm{wt} \%$ and $6 \mathrm{wt} \%$. The study showed that all the tested catalysts possessed good catalytic activities at $\sim 125^{\circ} \mathrm{C}-150^{\circ} \mathrm{C}$ temperature range except for $\mathrm{Rh}$ which is very active even at room temperature. Treatment of the catalyst with $\mathrm{Ir}$ or $\mathrm{Re}$ enhanced the hydrogenation activity of the Pt catalyst, while only $\mathrm{Ir} / \mathrm{Al}_{2} \mathrm{O}_{3}$ and $\mathrm{Re} /$ $\mathrm{Al}_{2} \mathrm{O}_{3}$ showed lower hydrogenation activity compared with Pt-Ir $/ \mathrm{Al}_{2} \mathrm{O}_{3}$ and $\mathrm{Pt}-\mathrm{Re} /$ $\mathrm{Al}_{2} \mathrm{O}_{3}$ respectively. The activity follows the order $\mathrm{Ir} / \mathrm{Al}_{2} \mathrm{O}_{3} \& \mathrm{Re} / \mathrm{Al}_{2} \mathrm{O}_{3}<\mathrm{Pt}, \mathrm{Re}$ $\& \mathrm{Ir}<\mathrm{Pt}-\mathrm{Ir} / \mathrm{Al}_{2} \mathrm{O}_{3} \& \mathrm{Pt}-\mathrm{Re} / \mathrm{Al}_{2} \mathrm{O}_{3}$. The use of $\mathrm{U}$ inhibit the activity with Pt-U/ $\mathrm{Al}_{2} \mathrm{O}_{3}$ showing even lower activity than $\mathrm{Pt} / \mathrm{Al}_{2} \mathrm{O}_{3}$ but higher than $\mathrm{U} / \mathrm{Al}_{2} \mathrm{O}_{3}$. All the halogenated catalysts promote the activity of the catalyst. Catalyst with $3 \mathrm{wt} \% \mathrm{~F}$ or $\mathrm{Cl}$ showed highest activities for both benzene and toluene hydrogenation. This may be due to improving $\mathrm{H}_{2}$ spillover and increasing metal dispersion into the support. The $6 \mathrm{wt} \%$ treatment may have decrease the $\mathrm{H}_{2}$ spillover by decreasing the number of $-\mathrm{OH}$ group as $\mathrm{H}_{2}$ moves to active metal crystalline. The addition of $\mathrm{Cl}$ and $\mathrm{F}$ enhanced the catalyst activity to $21 \%$ and $18 \%$ benzene, and $25 \%$ and $30 \%$ toluene respectively from $4.2 \%$ and $5.4 \%$ benzene and toluene at $\sim 150{ }^{\circ} \mathrm{C}$ temperature. Halogen treatment on the $\mathrm{Pt}-\mathrm{Rh} / \mathrm{Al}_{2} \mathrm{O}_{3}$ showed an exceptionally higher activity for both benzene and toluene. Benzene and toluene hydrogenation reached $>90 \%$ and $100 \%$ respectively even at lower temperature $\left(50^{\circ} \mathrm{C}\right)$ which was maintained up to $\sim 175^{\circ} \mathrm{C}$. Recently, Soni and Sharma have employed nano-sized Pd-Clay (montmorillonite) for the hydrogenation of squalene surface modification of the clay and metal intercalation simultaneously occurred during wet impregnation. ${ }^{92}$ The Pd-nanoparticles-intercalated clay with a dominating Pd(1 111$)$ facet showed the highest reactivity and selectivity. The catalyst was stable with very low $\operatorname{Pd}$ leaching $(\approx 0.03 \mathrm{ppm})$ and was recyclable without losing any significant catalytic activity. In general, the hydrogenation activities of the tested catalyst highly improved in the presence of the halogenation treatment compared to unhalogenated ones. Some recently published literature identified $\mathrm{Ni} / \mathrm{Co}$-natural clay systems as good candidates for the upgrading reactions like hydrodeoxygenation (HDO) and/or hydrodenitrogenation (HDN) encountered during fuel production. 
According to Soni et al., the HDO process provided higher carbon atom economy and energy value over decarboxylation/decarbonylation, while further reducing the formation of greenhouse gases such as $\mathrm{CO}_{2}$ and $\mathrm{CH}_{4} \cdot{ }^{93}$ Total yield of saturated hydrocarbons from algae oil valorisation was $84-86 \mathrm{wt} \%$ with similar selectivity. The HDO rates of different fatty acids present in the algae oil were independent of the fatty acid chain length. The catalysts were cost-effective and recyclable, and metal leaching during hydroprocessing was less than $1 \mathrm{ppm}$ in all cases. This process is advantageous in terms of metal-to-substrate ratio, use of solvents and their concentration, and comparable HDO selectivity over the previously reported catalysts. A hydroprocessing reaction was also performed under solvent free conditions, which could be useful in industrial applications. Therefore, the claysupported catalysts have good refining potentials for upgrading fuel feeds.

\section{CONCLUSION AND OUTLOOK}

Hydrogenation is an important catalytic process recently prioritised by the petroleum refineries for the production of high-quality gasoline suitable for application in modern and re-configured automobile engines. Mechanistically, the process proceeds through $\mathrm{C}-\mathrm{C}$ bond cleavages involving hydrogen addition, saturation of $\mathrm{C}=\mathrm{C}$ bonds in olefins/aromatics, ring opening of cyclic compounds and isomerisation in certain circumstances.

Catalytic parameters identified very influential during the process include hydrogen pressure, reaction temperature, catalyst nature and composition, and the nature of the reaction feed. Metal promoted oxides and modified zeolites have so far demonstrated good hydrogenation activity. However, the challenges of catalyst deactivation by coke precursors and consequent pore-blockage are not yet resolved.

There are numerous issues that should be fully evaluated in order to actualise the overall process in economic and scientific efficiency. The role of catalyst preparation conditions such as hydrothermal conditions, impregnation/deposition/ precipitation and the subsequent calcination conditions on the generation of catalytically active sites and their associated stability under variable reaction conditions must be fully explored. Hydrogenolysis is a common problem encountered with the oxides supported $\mathrm{Pd}, \mathrm{Pt}$ and $\mathrm{Ni}$ catalysts especially at higher loadings exceeding $5 \mathrm{wt} \%$. It is therefore very vital to establish the optimal and workable metal loadings. Clearly, hydrogenolysis of the hydrocarbons generates free radical species that can trigger chain reactions and consequent evolution of unwanted gaseous products with carbon numbers below the gasoline range. 
Zeolite catalysts should be designed in the nano- and hierarchical (i.e., mesoporous scale) forms in order to fully eliminate the problems of diffusional limitations. When the diffusion of reactants/reaction products is hindered, cracking and carbonaceous deposition becomes prominent and the catalytic activity decays rapidly. Another area to be explored includes the influence of Si/Al ratio (i.e., zeolite acidity) and topological properties on the overall reaction mechanism and the yield of desired gasoline range hydrocarbons.

\section{ACKNOWLEDGEMENTS}

The authors are grateful to the Petroleum Technology Development Fund (PTDF), Abuja, Nigeria for a PhD scholarship to Mr. Garba and sponsorship of the publication (grant number: PTDF/E/OSS/PHD/GMD/655/14/). Galadima and Garba are also immensely grateful to Tertiary Education Trust Fund (TETFund), Nigeria for a research funding to Federal University Gusau through Institutional Based Research (IBR) scheme Batch 1 with reference number TETFUND/DESS/ UNI/GUSAU/RP/VOL.1 for Environmental Sustainability Research.

\section{REFERENCES}

1. Agarwal, A. K. et al. (2015). Emission profiling of diesel and gasoline cars at a city traffic junction. Particuol., 18, 186-193, https://doi.org/10.1016/j. partic.2014.06.008.

2. Ou, J. et al. (2015). Concentrations and sources of non-methane hydrocarbons (NMHCs) from 2005 to 2013 in Hong Kong: A multi-year real-time data analysis. Atmosph. Environ., 103, 196-206, https://doi.org/10.1016/j. atmosenv.2014.12.048.

3. Erofeev, V. I. et al. (2014). Production of high-octane gasoline from straightrun gasoline on ZSM-5 modified zeolites. Theor. Found. Chem. Eng., 48(1), 71-76, https://doi.org./10.1134/S0040579514010023.

4. Song, H. et al. (2015). La-Ni modified S2O82-/ZrO2-A12O3 catalyst in n-pentane hydroisomerization. Catal. Comm., 59, 61-64, https://doi.org/ 10.1016/j.catcom.2014.09.037.

5. Galadima, A. et al. (2012). n-Alkane hydroconversion over carbided molybdena supported on sulfated zirconia. Appl. Petrochem. Res., 1(1-4), 35-43, https://doi.org/10.1007/s13203-011-0004-0.

6. Erlbaum, N. (1976). Gasoline demand by owner characteristics. Transport. Res. Rec., 561, 37-44.

7. Chang, M. (1976). Gasoline consumption in urban traffic. Transport. Res. Rec., 599, 25-30. 
8. Tom, J. T. et al. (2015). Fitzgibbon perspectives on down stream oil and gas. In (Ed.) McKinsey \& Co. Profitability in a world of over capacity. Houston: McKinsey \& Co.

9. Tang, J. L. (2012). Naphthenic ring opening of perhydrophenanthrene over zeolite catalysts. J. Fuel Chem. Technol., 40(6), 721-726, https://doi. org/10.1016/S1872-5813(12)60028-0.

10. Girgis, M. J. et al. (1991). Reactivities, reaction networks, and kinetics in high-pressure catalytic hydroprocessing. Ind. Eng. Chem. Res., 30(9), 20212058, https://doi.org/10.1021/ie00057a001.

11. Bond, G.C.(1958). The catalytic hydrogenation of unsaturated hydrocarbons. Part I. The kinetics of the hydrogenation of acetylene over a nickelpumice catalyst. J. Chem. Soc., 0, 2705-2719, https://doi.org/10.1039/ JR9580002705.

12. Jackson, S. D. et al. (2007). Hydrogenation of unsaturated hydrocarbons - 40 years on: Hydrogenation of 1,3-pentadiene over Pd/alumina. Catal. Today, 128(1-2), 47-51, https://doi.org/10.1016/j.cattod.2007.04.013.

13. Winiarek, P. et al. (1998). Hydrogenation of unsaturated hydrocarbons over alkali-metal-modified zinc oxide. J. Chem. Soc. Farad. Trans., 94(1), 167172, https://doi.org/10.1039/A704988I.

14. Boitiaux, J. P. et al. (1987). Liquid phase hydrogenation of unsaturated hydrocarbons on palladium, platinum and rhodium catalysts. Part II: Kinetic study of 1-butene, 1,3-butadiene and 1-butyne hydrogenation on rhodium; comparison with platinum and palladium. Appl. Catal., 32, 169-183, https://doi.org/10.1016/S0166-9834(00)80623-5.

15. Topsøe, H. et al. (1996). Hydrotreating catalysis. In (Eds.) Anderson, J. R. \& Boudart, M. Catalysis: Science and technology. Heidelberg: Springer.

16. Ellis, J. et al. (1994). Removal of nitrogen compounds from hydrotreated shale oil by adsorption on zeolite. Fuel, 73(10), 1569-1573, https://doi. org/10.1016/0016-2361(94)90133-3.

17. Froment, G. F. et al. (1997). Kinetics of the catalytic removal of the sulphur components from the light cycle oil of a catalytic cracking unit. Stud. Surf. Sci. Catal., 106, 83-97, https://doi.org/10.1016/S0167-2991(97)80008-0.

18. Morel, F. et al. (1997). Processes and catalysts for hydrocracking of heavy oil and residues. Stud. Surf. Sci. Catal., 106, 1-16, https://doi.org/10.1016/ S0167-2991(97)80003-1.

19. Do, P. T. M. et al. (2007). Catalytic strategies for improving specific fuel properties. Catal., 20, 33-64, https://doi.org/10.1039/B602366P.

20. Charles, F. L. et al. (1991). Hydrotreating optimization: Conclusion optimization of catalyst system reaps economic benefits. Oil and gas Journal Magazine, 6 March. 
21. Meille, V. et al. (1997). Hydrodesulfurization of alkyldibenzothiophenes over a NiMo/ $/ \mathrm{Al}_{2} \mathrm{O}_{3}$ catalyst: Kinetics and mechanism. J. Catal., 170(1), 29-36, https:// doi.org/10.1006/jcat.1997.1732.

22. Meille, V. et al. (1999). Hydrodesulfurization of 4-methyl-dibenzothiophene: A detailed mechanistic study. Appl. Catal. A Gen., 187(2), 179-186, https://doi.org/10.1016/S0926-860X(99)00135-0.

23. Houalla, M. et al. (1980). Hydrodesulfurization of methyl-substituted dibenzothiophenes catalyzed by sulfided $\mathrm{Co}-\mathrm{Mo \gamma}-\mathrm{Al}_{2} \mathrm{O}_{3}$. J. Catal., 61(2), 523-527, https://doi.org/10.1016/0021-9517(80)90400-5.

24. Knudsen, K. G. et al. (1999). Catalyst and process technologies for ultra low sulfur diesel. Appl. Catal. A Gen., 189(2), 205-215, https://doi.org/10.1016/ S0926-860X(99)00277-X.

25. Lamure-Meille, V. et al. (1995). Effect of experimental parameters on the relative reactivity of dibenzothiophene and 4-methyldibenzothiophene. Appl. Catal. A Gen., 131(1), 143-157, https://doi.org/10.1016/0926860X(95)00118-2.

26. Landau, M. V. et al. (1996). Hydrodesulfurization of methyl-substituted dibenzothiophenes: Fundamental study of routes to deep desulfurization. J. Catal., 159(1), 236-245, https://doi.org/10.1006/jcat.1996.0083.

27. Ancheyta-Juárez, J. et al. (1999). Hydrotreating of straight run gas oillight cycle oil blends. Appl. Catal. A Gen., 180(1-2), 195-205, https://doi. org/10.1016/S0926-860X(98)00351-2.

28. Schulz, H. et al. (1999). Gas oil deep hydrodesulfurization: Refractory compounds and retarded kinetics. Catal. Today, 49(1-3), 87-97, https://doi. org/10.1016/S0920-5861(98)00412-X.

29. Qian, W. et al. (1999). Hydrodesulfurization of dibenzothiophene and hydrogenation of phenanthrene on alumina-supported Pt and Pd catalysts. Appl. Catal. A Gen., 184(1), 81-88, https://doi.org/10.1016/S0926-860X(99) 00083-6.

30. Robinson, W. R. A. M. et al. (1999). Development of deep hydrodesulfurization catalysts. II: NiW, Pt and Pd catalysts tested with (substituted) dibenzothiophene. Fuel Process. Technol., 61(1-2), 103-116, https://doi.org/10.1016/S0378-3820(99)00032-6.

31. de Bont, P. W. et al. (2000). Molybdenum-sulfide particles inside NaY zeolite as a hydrotreating catalyst prepared by adsorption of $\mathrm{Mo}(\mathrm{CO}) 6$. Appl. Catal. A Gen., 202(1), 99-116, https://doi.org/10.1016/S0926-860X(00)00458-0.

32. Okamoto, Y. (1997). Preparation and characterization of zeolite-supported molybdenum and cobalt-molybdenum sulfide catalysts. Catal. Today, 39(1-2), 45-59, https:// doi.org/10.1016/S0920-5861(97)00087-4. 
33. Sugioka, M. et al. (1997). Noble metals supported on mesoporous silicate FSM-16 as new hydrodesulfurization catalyst. Catal. Today, 39(1-2), 6167, https://doi.org/10.1016/S0920-5861(97)00088-6.

34. Sakanishi, K. et al. (2000). Hydrodesulfurization kinetics and mechanism of 4,6-dimethyldibenzothiophene over NiMo catalyst supported on carbon. J. Mol. Catal. A Chem., 155(1-2), 101-109, https://doi.org/10.1016/S13811169(99)00323-4.

35. Farag, H. et al. (2000). Fundamental comparison studies on hydrodesulfurization of dibenzothiophenes over CoMo-based carbon and alumina catalysts. Appl. Catal. A Gen., 194-195, 147-157, https://doi. org/10.1016/S0926-860X(99)00363-4.

36. Egorova, M. et al. (2006). The role of Ni and Co promoters in the simultaneous HDS of dibenzothiophene and HDN of amines over Mo/ $\gamma$-Al2O3 catalysts. J. Catal., 241(1), 162-172, https://doi.org/10.1016/j.jcat.2006.04.011.

37. Wang, X. et al. (2015). Effect of promoters on the HDS activity of aluminasupported Co-Mo sulfide catalysts. RSC Adv., 5(121), 99706-99711, https://doi.org/10.1039/C5RA17414G.

38. Boitiaux, J. P. et al. (1985). Hydrogenation of highly unsaturated hydrocarbons over highly dispersed Pd catalyst. Appl. Catal., 15(2), 317-326, https://doi.org/10.1016/S0166-9834(00)81845-X.

39. Bos, A. N. R. et al. (1993). Mechanism and kinetics of the selective hydrogenation of ethyne and ethene. Chem. Eng. Process. Process Intens., 32(1), 1-7, https://doi.org/10.1016/0255-2701(93)87001-B.

40. Luo, M. et al. (2015). $\mathrm{Al}\left(\mathrm{CH}_{3}\right) 3$-promoted Pt/MCM-41 catalysts for tetralin hydrogenation in the presence of benzothiophene and promotion mechanism of Al-promoted Pt/MCM-41 catalysts. RSC Adv., 5(53), 42468-42476, https://doi.org/10.1039/C5RA04771D.

41. Stanislaus, A. et al. (1994). Aromatic hydrogenation catalysis: A review. Catal. Rev., 36(1), 75-123, https://doi.org/10.1080/01614949408013921.

42. Garba, M. D. et al. (2016). Catalytic upgrading of refinery cracked products by trans-hydrogenation: A review. Appl. Petrochem. Res., 1-8, https://doi. org/10.1007/s13203-016-0173-y.

43. Hauwert, P. et al. (2010). Mechanism of $\mathrm{Pd}(\mathrm{NHC})$-catalyzed transfer hydrogenation of alkynes. J. Am. Chem. Soc., 132(47), 16900-16910, https://doi.org/10.1021/ja1062407.

44. Hamilton, C. A. et al. (2002). Competitive reactions in alkyne hydrogenation. Appl. Catal. A Gen., 237(1-2), 201-209, https://doi.org/10.1016/S0926860X(02)00332-0.

45. Canning, A. S. et al. (2006). C-5 alkene hydrogenation: Effect of competitive reactions on activity and selectivity. Catal. Today, 116(1), 22-29, https://doi. org/10.1016/j.cattod.2006.04.002. 
46. Boitiaux, J. P. et al. (1987). Liquid phase hydrogenation of unsaturated hydrocarbons on palladium, platinum and rhodium catalysts. Part I: Kinetic study of 1-butene, 1,3-butadiene and 1-butyne hydrogenation on platinum. Appl. Catal., 32, 145-168, https://doi.org/10.1016/S0166-9834(00)80622-3.

47. TransportPolicy.net. (2015). EU fuels: Diesel and gasoline. Retrieved from http://www.transportpolicy.net/index.php?title=EU:_Fuels:_Diesel_and_ Gasoline on 15 June 2016.

48. Flego, C. etal.(2009).A comprehensive two-dimensional gas chromatography coupled with quadrupole mass spectrometry approach for identification of C10 derivatives from decalin. J. Chromatogr. A, 1216(14), 2891-2899, https://doi.org/10.1016/j.chroma.2008.10.110.

49. Berger, C. et al. (2003). Hydroconversion of methylcyclohexane on TEOSmodified H-ZSM-5 zeolite catalysts: Production of a high-quality synthetic steamcracker feedstock. Microp. Mesop. Mater, 59(1), 1-12, https://doi. org/10.1016/S1387-1811(03)00270-1.

50. Kubička, D. et al. (2004). Ring opening of decalin over zeolites: I. Activity and selectivity of proton-form zeolites. J. Catal., 222(1), 65-79, https://doi. org/10.1016/j.jcat.2003.10.027.

51. Castaño, P. et al. (2008). Kinetic modelling of methylcyclohexane ringopening over a HZSM-5 zeolite catalyst. Chem. Eng. J., 140(1-3), 287-295, https://doi.org/10.1016/j.cej.2007.09.041.

52. Santikunaporn, M. et al. (2004). Ring opening of decalin and tetralin on HY and Pt/HY zeolite catalysts. J. Catal., 228(1), 100-113, https://doi. org/10.1016/j.jcat.2004.08.030.

53. Slagtern, A. et al. (2010). Cracking of cyclohexane by high Si HZSM5. Appl. Catal. A Gen., 375(2), 213-221, https://doi.org/10.1016/j. apcata.2009.12.032.

54. Cerqueira, H. S. et al. (2001). Methylcyclohexane transformation over HFAU, HBEA, and HMFI zeolites: I. Reaction scheme and mechanisms. Ind. Eng. Chem. Res., 40(4), 1032-1041, https://doi.org/10.1021/ie000730f.

55. McVicker, G. B. et al. (2002). Selective ring opening of naphthenic molecules. J. Catal., 210(1), 137-148, https://doi.org/10.1006/jcat.2002.3685.

56. Gault, F. G. (1981). Mechanisms of skeletal isomerization of hydrocarbons on metals. Adv. Catal., 30, 1-95, https://doi.org/10.1016/S0360-0564(08) 60325-9.

57. Paal, Z. et al. (1977). A new classification of metal catalysts in skeletal reactions of hydrocarbons. Nature, 267(5608), 234-236.

58. Lecarpentier, S. et al. (2008). Study of $\mathrm{Ir} / \mathrm{WO} / \mathrm{ZrO} 2-\mathrm{SiO} 2$ ring-opening catalysts: Part II. Reaction network, kinetic studies and structureactivity correlation. J. Catal., 254(1), 49-63, https://doi.org/10.1016/j. jcat.2007.11.016. 
59. Samoila, P. et al. (2009). Selective ring-opening of methylcyclopentane on platinum-based bimetallic catalysts. Appl. Catal. A Gen., 369(1-2), https://doi.org/10.1016/j.apcata.2009.09.006.

60. Do, P. T. et al. (2006). Ring opening of 1,2- and 1,3-dimethylcyclohexane on iridium catalysts. J. Catal., 238(2), 477-488, https://doi.org/10.1016/j. jcat.2005.12.021.

61. Chamam, M. et al. (2007). Characterization and catalytic properties of Rh$\mathrm{Sn} / \mathrm{Al}_{2} \mathrm{O}_{3}$ catalyst prepared by organometallic grafting. Appl. Catal. A Gen., 332(1), 27-36, https://doi.org/10.1016/j.apcata.2007.07.044.

62. Chimentão, R. J. et al. (2007). Hydrogenolysis of methylcyclopentane over the bimetallic $\mathrm{Ir}-\mathrm{Au} / \gamma-\mathrm{Al}_{2} \mathrm{O}_{3}$ catalysts. Appl. Surf. Sci., 253(13), 5888-5893, https://doi.org/10.1016/j.apsusc.2006.12.061.

63. Paál, Z. et al. (2007). Preparation, physical characterization and catalytic properties of unsupported Pt-Rh catalyst. J. Catal., 250(2), 254-263, https://doi.org/10.1016/j.jcat.2007.06.012.

64. Espinosa, G. et al. (2000). Catalytic behavior and active sites structure of PtAu/A12O3 bimetallic catalysts prepared by surface redox reactions. J. Mol. Catal. A Chem., 164(1-2), 253-262, https://doi.org/10.1016/S13811169(00)00347-2.

65. Moraes, R. et al. (2013). Ring opening of decalin and methylcyclohexane over bifunctional Ir/WO3/A12O3 catalysts. J. Catal., 299, 30-43, https://doi. org/10.1016/j.jcat.2012.11.017.

66. Arribas, M. A. et al. (2004). The role of metal sites during the coupled hydrogenation and ring opening of tetralin on bifunctional $\mathrm{Pt}(\mathrm{Ir}) / \mathrm{USY}$ catalysts. Appl. Catal. A Gen., 267 (1-2), 111-119, https://doi.org/10.1016/j. apcata.2004.02.037.

67. D'Ippolito, S. A. et al. (2015). Selective ring opening of methylcyclohexane and decalin over Rh-Pd supported catalysts: Effect of the preparation method. Fuel Process. Technol., 140, 180-187, https://doi.org/10.1016/j. fuproc.2015.08.027.

68. D'Ippolito, S. A. et al. (2015). Influence of the support on the selective ring opening of methylcyclohexane and decalin catalyzed by $\mathrm{Rh}-\mathrm{Pd}$ catalysts. J. Mol. Catal. A Chem., 398, 203-214, https://doi.org/10.1016/j. molcata.2014.12.011.

69. Vu, T. N. et al. (2005). Platinum tungstated zirconia isomerization catalysts: Part I. Characterization of acid and metal properties. J. Catal., 231(2), 453467, https://doi.org/10.1016/j.jcat.2005.01.037.

70. Lecarpentier, S. et al. (2007). Use of a catalyst for opening hydrocarbon rings. Paris: Total France Tour France. 
71. Santi, D. (2013). High-performance ring-opening catalysts based on iridiumcontaining zeolite Beta in the hydroconversion of decalin. Appl. Catal. A Gen., 455, 46-57, https://doi.org/10.1016/j.apcata.2013.01.020.

72. Vicerich, M.A. et al. (2014). Influence of Na content on the catalytic properties of Pt-Ir/Al2O3 catalysts for selective ring opening of decalin. Appl. Catal. A Gen., 480, 42-49, https://doi.org/10.1016/j.apcata.2014.04.036.

73. Petzny, W. J. (1999). Aromatics: Bridging refining and petrochemicals - A major challenge for the future. DGMK Tagungsber., 9903, 7-20.

74. Onyestyák, G. et al. (2002). Cyclohexane conversion over H-zeolite supported platinum. Appl. Catal. A Gen., 229(1-2), 65-74, https://doi. org/10.1016/S0926-860X(02)00016-9.

75. Shimizu, K. et al. (2001). Catalytic activity for synthesis of isomerized products from benzene over platinum-supported sulfated zirconia. Appl. Catal. A Gen., 206(1), 79-86, https://doi.org/10.1016/S0926860X(00)00593-7.

76. Cunha, D. S. et al. (2002). Hydrogenation of benzene and toluene over Ir particles supported on $\gamma$-Al2O3. Appl. Catal. A Gen., 236(1-2), 55-66, https://doi.org/10.1016/S0926-860X(02)00275-2.

77. Lin, S. D. et al. (1993). Hydrogenation of aromatic hydrocarbons over supported Pt catalysts. I: Benzene hydrogenation. J. Catal., 143(2), 539553, https://doi.org/10.1006/jcat.1993.1297.

78. Lietz, G. et al. (1976). Low temperature hydrogenolysis and hydrogenation of alkylbenzenes on platinum catalysts. J. Catal., 45(2), 121-127, https://doi.org/10.1016/0021-9517(76)90127-5.

79. Fu, J. Z. et al. (1995). Studies on the acidity-reducibility and catalytic properties of NiHY zeolite. Chem. J. Chin. Uni., 16(3), 461.

80. Li, W. et al. (2005). Novel Ni2Mo3N/zeolite catalysts used for aromatics hydrogenation as well as polycyclic hydrocarbon ring opening. Catal. Comm., 6(10), 656-660, https://doi.org/10.1016/j.catcom.2005.05.016.

81. Kustov, L. M. (2011). Opening of the rings of aromatic and naphthene hydrocarbons: A new way of improving the quality of fuels. Catal. Ind., 3(4), 358-369, https://doi.org/10.1134/s2070050411040040.

82. Venezia, A. M. et al. (2004). Hydrogenation of aromatics over $\mathrm{Au}-\mathrm{Pd} / \mathrm{SiO} 2-$ Al2O3 catalysts: Support acidity effect. Appl. Catal. A Gen., 264(1), 43-51, https://doi.org/10.1016/j.apcata.2003.12.025.

83. Ali, A. et al. (1998). Hydrogenation of aromatics on modified platinumalumina catalysts. Appl. Catal. A Gen., 170(2), 285-296, https://doi.org/ 10.1016/S0926-860X(98)00058-1.

84. Pawelec, B. et al. (2002). Hydrogenation of aromatics over supported Pt-Pd catalysts. Appl. Catal. A Gen., 225(1-2), 223-237, https://doi.org/10.1016/ S0926-860X(01)00868-7. 
85. Schimpf, S. et al. (2002). Supported gold nanoparticles: In-depth catalyst characterization and application in hydrogenation and oxidation reactions. Catal. Today, 72(1-2), 63-78, https://doi.org/10.1016/S09205861(01)00479-5.

86. Hutchings, G. J. (2002). Gold catalysis in chemical processing. Catal. Today, 72(1-2), 11-17, https://doi.org/10.1016/S0920-5861(01)00473-4.

87. Erkelens, J. et al. (1963). Some reactions of cyclohexene with hydrogen and deuterium on evaporated gold films. Trans. Farad. Soc., 59, 1181-1191, https://doi.org/10.1039/TF9635901181.

88. Chambers, R. P. et al. (1966). Selectivity of gold for hydrogenation and dehydrogenation of cyclohexene. J. Catal., 5(3), 517-528, https://doi.org/ 10.1016/S0021-9517(66)80070-2.

89. Bond, G. C. et al. (1996). Catalytic hydrogenation in the liquid phase. Part 1: Hydrogenation of isoprene catalysed by palladium, palladium-gold and palladium-silver catalysts. J. Mol. Catal. A Chem., 109(3), 261-271, https://doi.org/10.1016/1381-1169(96)00027-1.

90. Bonarowska, M. et al. (2002). Pd-Au/sibunit carbon catalysts: Characterization and catalytic activity in hydrodechlorination of dichlorodifluoromethane (CFC-12). J. Catal., 209(2), 528-538, https://doi. org/10.1006/jcat.2002.3650.

91. Sárkány, A. et al. (2002). Hydrogenation of acetylene over low loaded $\mathrm{Pd}$ and $\mathrm{Pd}-\mathrm{Au} / \mathrm{SiO} 2$ catalysts. Appl. Catal. A Gen., 229(1-2), 117-125, https://doi.org/10.1016/S0926-860X(02)00020-0.

92. Soni, K. B. \& Sharma, K. R. (2016). Palladium-nanoparticles-intercalated montmorillonite clay: A green catalyst for the solvent-free chemoselective hydrogenation of squalene. Chem. Cat. Chem. Catal., 8(10), 1763-1768, https://doi.org/10.1002/cctc.201600210.

93. Soni, V. K. et al. (2017). Ni/Co-natural clay as green catalysts for microalgae oil to diesel grade hydrocarbons conversion. ACS Sustain. Chem. Eng., 5(6), 5351-5359, https://doi.org/10.1021/acssuschemeng.7b00659. 